\title{
Nitric Oxide and ATP-Sensitive Potassium Channels Mediate Lipopolysaccharide-Induced Depression of Central Respiratory-Like Activity in Brain Slices
}

\author{
An-dong Lu ${ }^{a, b}$ Jia-feng Wang ${ }^{a} \quad$ Yong-hua Chen $^{b} \quad$ Li-li Hou $^{b} \quad$ Xu-jiao Zhou ${ }^{b}$ \\ Jin-jun Bian ${ }^{a} \quad J$-jiang Wang ${ }^{b}$ Ke-ming Zhu ${ }^{a}$ \\ aDepartment of Anesthesiology and Intensive Care Medicine, Changhai Hospital, the Second Military Medical \\ University, and b The State Key Laboratory of Medical Neurobiology and Institute of Brain Sciences, Fudan \\ University Shanghai Medical College, Shanghai, China
}

\section{Key Words}

Respiratory activity $\cdot$ Lipopolysaccharide $\cdot$ Nitric oxide $•$ ATP-sensitive potassium channels

\begin{abstract}
Infection may result in early abnormalities in respiratory movement, and the mechanism may involve central and peripheral factors. Peripheral mechanisms include lung injury and alterations in electrolytes and body temperature, but the central mechanisms remain unclear. In the present study, brainstem slices harvested from rats were stimulated with lipopolysaccharide at different doses. Central respiratory activities as demonstrated by electrophysiological activity of the hypoglossal rootlets were examined and the mechanisms were investigated by inhibiting nitric oxide synthase and ATP-sensitive potassium channels. As a result, $0.5 \mu \mathrm{g} / \mathrm{ml}$ lipopolysaccharide mainly caused inhibitory responses in both the frequency and the output intensity, while $5 \mu \mathrm{g} / \mathrm{ml}$ lipopolysaccharide caused an early frequency increase followed by delayed decreases in both the frequency and the output intensity. At both concentrations
\end{abstract}

An-dong Lu, Jia-feng Wang and Yong-hua Chen contributed equally to this work.

\section{KARGER \\ Fax +41613061234 \\ E-Mail karger@karger.ch}

() 2012 S. Karger AG, Base

www.karger.com the inhibitory responses were fully reversed by inhibition of nitric oxide synthase with $\mathrm{N} \omega$-nitro-L-arginine methyl ester hydrochloride $(20 \mu \mathrm{M})$, and by inhibition of ATPsensitive potassium channels with glybenclamide $(100 \mu \mathrm{M})$. These results show that direct lipopolysaccharide challenge altered central respiratory activity in dose- and timerelated manners. Nitric oxide synthase and ATP-sensitive potassium channels may be involved in the respiratory changes.

Copyright ๑ 2012 S. Karger AG, Basel

\section{Introduction}

Respiratory movement consists of a series of sequential physiological processes including rhythmogenesis in the medulla, transmission of excitatory drive from rhythmogenesis neurons to motoneurons, and control of respiratory muscles by respiratory motor nerves. Rhythmogenesis center plays a central role in these processes, and is regulated by a variety of physiological mechanisms including pulmonary mechanical and chemoreflexes, arte-
Dr. Ke-ming Zhu may also be contacted for further correspondence at: Department of Anesthesiology and Intensive Care Medicine

Changhai Hospital, the Second Military Medical University Shanghai 200433 (China)

Tel. +86 218187 3497, E-Mail kmzhu_md@yahoo.com.cn

Ji-jiang Wang

The State Key Laboratory of Medical Neurobiology

Institute of Brain Sciences, Fudan University Shanghai Medical College

Shanghai 200032 (China)

Tel. +86 215423 7857, E-Mail wangjj@ shmu.edu.cn 
rial chemoreflexes, and central chemoreceptor-mediated regulations [1].

Inflammation caused by infection is always accompanied with alterations in respiratory movement, which is a component of systemic inflammatory response syndrome (SIRS) [2]. The pathophysiological changes may be divided into peripheral and central mechanisms. The peripheral mechanism include acute lung injury (ALI)/ acute respiratory distress syndrome (ARDS), altered blood acid-base balance, insufficient tissue perfusion, hyper-/hypothermia, and so on, which have been the focus of many studies [3]. However, the central mechanism has not been well illustrated up to now.

According to the case reports presented by Hameed and Riordan [4], tachypnoea is an early feature of meningococcal disease, which might lead to misdiagnosis with bronchiolitis. Neuroinflammatory factors may also contribute to abnormalities in respiratory movement, including nitric oxide (NO) and prostaglandins, and some cytokines may be upregulated in the brain in several diseases, such as meningitis and septic encephalopathy. Some of these factors such as NO [5-18] and prostaglandins [1921] have been found to alter the frequency and the output intensity of central respiratory activity under both physiological and pathological conditions. Lipopolysaccharide (LPS) and interleukin- $1 \beta$ induced meningitis will result in disruption of blood brain barrier (BBB), blood-cerebrospinal fluid barrier (BCSFB) and blood-arachnoid barrier (BAB), as demonstrated by gadolinium-enhancement ratio imaging [22]. It was also demonstrated that small amount of LPS might penetrate across BBB, though the concentration might be too low to invoke any pathophysiological changes [23]. Nevertheless, little has been known regarding the effect of LPS on respiratory center. The present study was therefore performed to investigate the effect of LPS challenge on electrophysiological activity of respiratory center and also the potential mechanism.

\section{Materials and Methods}

\section{Slice Preparation}

The 4-5-day-old Sprague-Dawley rats (Shanghai Institute for Family Planning) were anesthetized deeply with halothane and decapitated at the supracollicular level. The brain was submerged in cold $\left(4^{\circ} \mathrm{C}\right)$ artificial cerebral spinal fluid (ACSF) of the following composition (in $\mathrm{mM}$ ): $\mathrm{NaCl} 124, \mathrm{KCl} 3.0, \mathrm{KH}_{2} \mathrm{PO}_{4} 1.2, \mathrm{CaCl}_{2}$ 2.4, $\mathrm{MgSO}_{4} 1.3, \mathrm{NaHCO}_{3} 26$, D-glucose 10, constantly bubbled with $95 \% \mathrm{O}_{2}-5 \% \mathrm{CO}_{2}$, pH 7.4. The cerebellum was removed and the hindbrain was isolated using a dissection microscope. The brainstem was then secured in the slicing chamber of a vibratome (Leica VT 1000S) filled with the same ACSF. The rostral end of the brainstem was set upwards and the dorsal surface was glued to an agar block facing the razor. The brainstem was sectioned serially in variable thickness in the transverse plane. Once the nucleus ambiguus was visible under the microscope, a single medulla slice of 600-800 $\mu \mathrm{m}$ thickness, of which one to two hypoglossal rootlets in each side were retained, was taken for experimentation. The thick medullary slice preparation generates rhythmic inspiratory-related discharge in hypoglossal rootlets [24]. The slice was transferred into the recording chamber and submerged in ACSF with a flow rate of $8-11 \mathrm{ml} / \mathrm{min}$. The temperature was maintained at $23 \pm 0.5^{\circ} \mathrm{C}$, and the concentration of $\mathrm{KCl}$ in $\mathrm{ACSF}$ was increased to $10 \mathrm{~mm}$ to allow steady recording of the respiratory rhythm.

\section{Electrophysiological Recording}

The activity of the hypoglossal rootlets was recorded using a suction electrode and was amplified with a BMA-931 bioamplifier $(5 \mathrm{kHz}$ sampling frequency; $10-1,000 \mathrm{~Hz}$ band pass; 20,000 times), electronically integrated $(\tau=200 \mathrm{~ms})$ with an MA-1000 Moving Averager (CWE Inc., Pa., USA) before feeding into the computer. All animal procedures were performed in compliance with the institutional guidelines at Fudan University, and are in accordance with the internationally accepted principles in the care and use of experimental animals.

\section{Drug Application}

LPS (from Escherichia coli 055:B5) was dissolved in ACSF to make a fresh stock solution of $5 \mathrm{mg} / \mathrm{ml}$, and was diluted to 0.5 or $5 \mu \mathrm{g} / \mathrm{ml}$ for use. LPS was usually applied continuously. In some slices LPS was applied for $30 \mathrm{~min}$ and the recovery process of respiratory responses to LPS application was watched. Glybenclamide, a selective inhibitor of ATP-sensitive potassium channels $\left(\mathrm{K}_{\mathrm{ATP}}\right)$, was dissolved in DMSO to make a stock solution of $100 \mathrm{mM}$, and was diluted with ACSF to 10 or $100 \mu \mathrm{M}$ for use. In experiments in which glybenclamide was used, DMSO was added to the perfusate throughout the experiment. $\mathrm{N \omega}$-nitro-L-arginine methyl ester hydrochloride (L-NAME), an inhibitor of NOS, was dissolved in ACSF to make a fresh stock solution of $10 \mathrm{mM}$, and was diluted to $20 \mu \mathrm{M}$ for use. All drugs were purchased from Sigma-Aldrich (St. Louis, Mo., USA).

\section{Data Analysis}

The frequency of hypoglossal bursts was manually counted and at least a 2-minute recording was analyzed to get an average. The amplitude, the duration and the area were analyzed with Clampfit software (Axon Instruments, USA), and at least 10 continuous bursts were analyzed to get an average. Results are presented as mean \pm SEM, and statistically compared with one-way ANOVA followed by Bonferroni's correction. Significant difference was set at $\mathrm{p}<0.05$.

\section{Results}

\section{$0.5 \mu \mathrm{g} / \mathrm{ml}$ LPS Mainly Caused Inhibitory Responses of Central Respiratory Activity}

In preliminary experiments, six slices were recorded for $5 \mathrm{~h}$ without application of LPS to observe the stability 


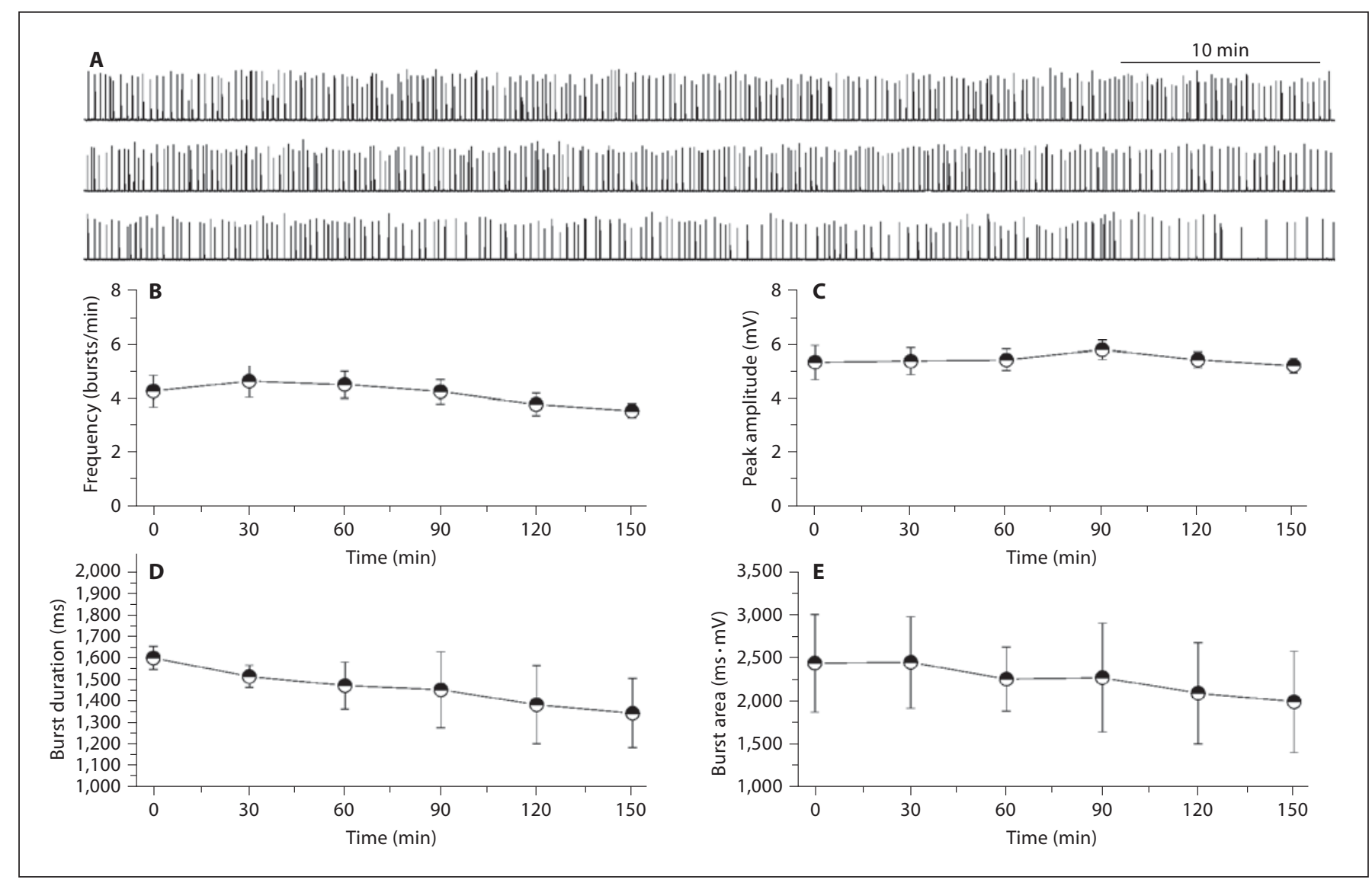

Fig. 1. The frequency and the intensity of hypoglossal bursts showed little time-related change under control recording. A Continuous recording of integrated hypoglossal activity from a representative experiment. B-E Summarized data from six slices of the time-related changes of the frequency (B), the peak amplitude (C), the burst duration (D), and the burst area (E).

of hypoglossal bursts. A representative experiment is shown in figure $1 \mathrm{~A}$, which shows that the frequency and the amplitude had little changes within the first $3 \mathrm{~h}$. Summarized data from all the six slices are presented in figure $1 \mathrm{~B}-\mathrm{E}$, which shows that the frequency, the amplitude, the duration and the area did not change significantly with time in $150 \mathrm{~min}$. In two slices, the frequency started to decline gradually after $3 \mathrm{~h}$; however, in none of the six slices was cessation of hypoglossal bursts observed within $5 \mathrm{~h}$.

In most (thirteen of fourteen) slices, application of 0.5 $\mu \mathrm{g} / \mathrm{ml}$ LPS caused slow but progressive decreases in the frequency and the duration of hypoglossal bursts. In one slice, the frequency, as well as the amplitude, was transiently increased in a period from 5 to 20 min after LPS application, but the duration had shown a decrease even when the frequency was at its highest value. A typical experiment is shown in figure $2 \mathrm{~A}$, and a sample burst about $60 \mathrm{~min}$ after
LPS application was compared with a control burst in figure $2 \mathrm{~B}$. In all the fourteen slices, the frequency and the duration were significantly lowered after $30 \mathrm{~min}$ LPS application, and were more profoundly inhibited after 60 and 90 min LPS application. However, the peak amplitude and area were not significantly altered at all the three time points after LPS application compared with control. The area at 90 min showed a significant decrease compared with the value at $60 \mathrm{~min}$. Figure $2 \mathrm{C}-\mathrm{F}$ shows the average values of the frequency, the peak amplitude, the duration, and the area of hypoglossal bursts, respectively, during control and 30, 60, and 90 min after LPS application.

In three of the fourteen slices, respiratory rhythm disappeared in 60-90 min after application of LPS. For statistic comparison, the frequency at $90 \mathrm{~min}$ in these three slices was regarded as zero, and the peak amplitude, the duration and the area were averaged from the last five 


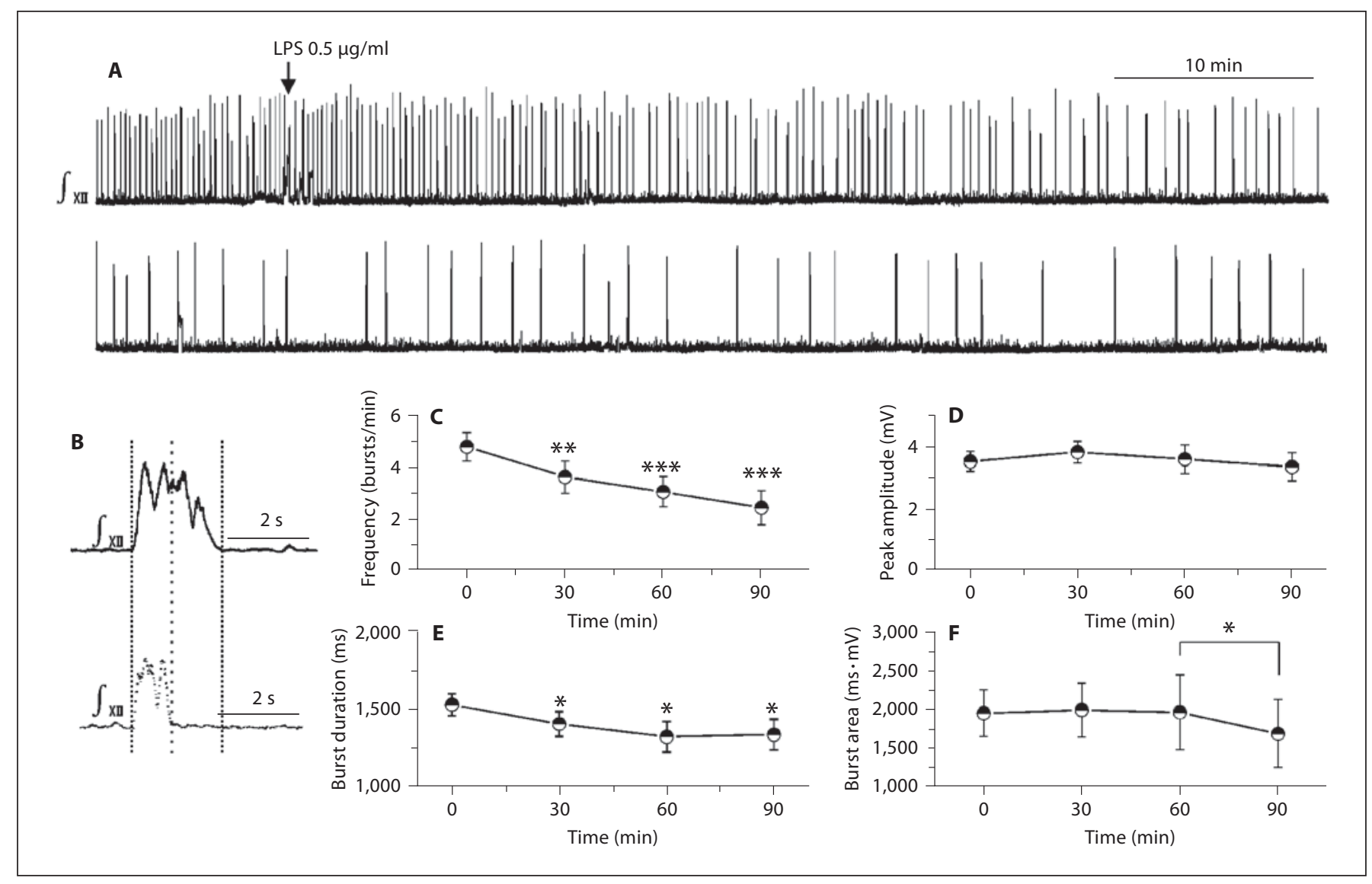

Fig. 2. $0.5 \mu \mathrm{g} / \mathrm{ml}$ LPS caused progressive inhibition of the frequency and intensity of central respiratory activity. A Recording of hypoglossal activity in a typical experiment. B Comparison of typical hypoglossal bursts during control (upper panel) and 60 min after application of LPS (lower panel), which shows the decreases in the duration and bursting area. C-F The averages of the frequency $(\mathbf{C})$, peak amplitude (D), duration (E), and bursting area (F) of hypoglossal bursts before (0 min) and 30, 60, and $90 \mathrm{~min}$ after LPS application. Note in $\mathbf{F}$, the area at $90 \mathrm{~min}$ showed a significant decrease compared with the value at $60 \mathrm{~min} .{ }^{*} \mathrm{p}<0.05$, ${ }^{* *} \mathrm{p}<0.01,{ }^{* * *} \mathrm{p}<0.001$ compared with control. $\int_{\mathrm{XII}}=$ Integrated hypoglossal activity.

crease, followed by a delayed progressive decrease, of the frequency. The frequency increase in these eleven slices usually started in 5-10 min, reached the peak in several min, and mostly returned to baseline level within $25 \mathrm{~min}$. In three slices, the frequency increase lasted for as long as $150 \mathrm{~min}$. In all the sixteen slices, the peak frequency increase is statistically significant compared with control (fig. 3C). The initial response of the peak amplitude was also inconsistent in individual slices, which could be an increase, a decrease, or lack of change. In addition, the changes in the frequency and the peak amplitude were often asynchronous. A frequency increase could be accompanied by increased, decreased, or unaltered peak amplitude. In contrast, in all the sixteen slices, the duration showed progressive decrease, even in periods during 


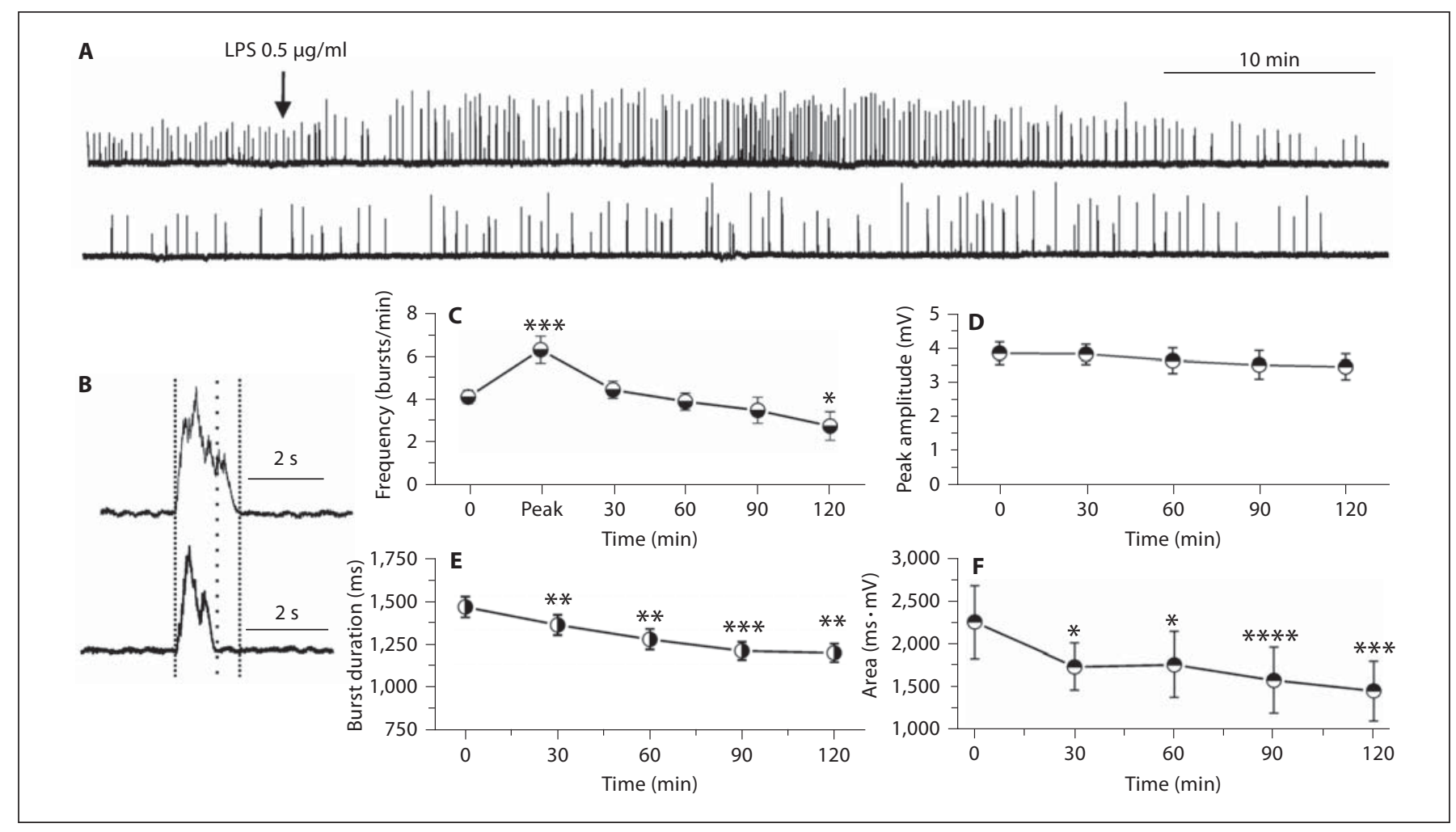

Fig. 3. $5 \mu \mathrm{g} / \mathrm{ml}$ LPS caused an early frequency increase and delayed decreases in both the frequency and intensity of central respiratory activity. A Recording of hypoglossal activity in a typical experiment. B Comparison of typical hypoglossal bursts during control (upper panel) and 90 min after application of LPS (lower panel), which shows the decreases in the duration and bursting area. C-F The averages of the frequency (C), peak amplitude (D), duration (E), and bursting area (F) of hypoglossal bursts before (0 min) and 30, 60, 90, and $120 \mathrm{~min}$ after LPS application. Note in $\mathbf{C}$, the frequency showed an early (within $25 \mathrm{~min}$ ) increase and a delayed decrease after LPS application. ${ }^{*} \mathrm{p}<0.05,{ }^{* *} \mathrm{p}<0.01$, ${ }^{* * *} \mathrm{p}<0.001,{ }^{* * *} \mathrm{p}<0.0001$ compared with control. which the frequency and/or the peak amplitude showed increases. A sample experiment that had typical biphasic frequency change is shown in figure $3 \mathrm{~A}$, and a sample burst about 90 min after LPS application was compared with a control burst in figure 3B. In all the sixteen slices, the frequency was significantly lowered by LPS application at $120 \mathrm{~min}$ (fig. 3C), the duration and area were significantly decreased at all the four time points analyzed (fig. 3E, F), but the peak amplitude was not significantly altered at all the time points analyzed (fig. 3D).

In four of the sixteen slices, respiratory rhythm disappeared in 100-115 min after application of LPS. For statistic comparison, the frequency at $120 \mathrm{~min}$ in these four slices was regarded as zero, and the peak amplitude, the duration and the area were averaged from the last five hypoglossal bursts after LPS application. 120 min after LPS application, in more and more slices, respiratory rhythm disappeared with time and data from individual hypoglossal bursts were not available. Thus only the data within 120 min were analyzed and compared in this section of experiments.

The responses of hypoglossal activity to LPS were largely irreversible. In four slices (two receiving $0.5 \mu \mathrm{g} /$ $\mathrm{ml}$ and two receiving $5 \mu \mathrm{g} / \mathrm{ml}$ LPS) LPS application was discontinued after $30 \mathrm{~min}$. All these four slices showed irreversible inhibition of hypoglossal respiratory activity in an observation period of 2.5-3.5 h.

\section{Glybenclamide Reversed the LPS-Induced Inhibition \\ of Respiratory Frequency and the Intensity of Motor \\ Output}

In twenty-one slices, after LPS $(0.5 \mu \mathrm{g} / \mathrm{ml}$ in twelve slices; $5 \mu \mathrm{g} / \mathrm{ml}$ in nine slices) had been applied for over $120 \mathrm{~min}$ or the respiratory rhythm had been abolished, $10 \mu \mathrm{M}$ glybenclamide was applied for $10 \mathrm{~min}$. This protocol slightly increased the frequency of respiration in four 


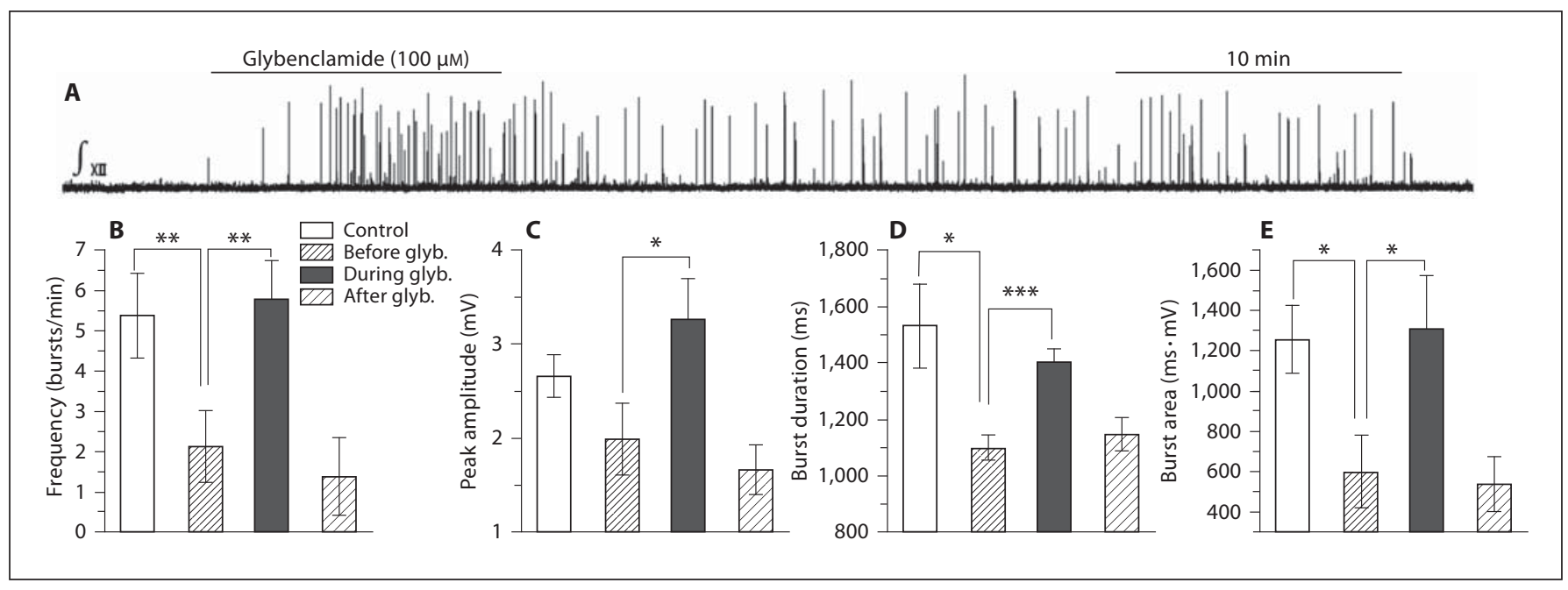

Fig. 4. Glybenclamide reversed the LPS-induced inhibition of central respiratory activity. A Recording of a sample experiment, which shows that glybenclamide $(100 \mu \mathrm{M})$ reversibly restored rhythmic hypoglossal bursts from LPS-induced respiratory silence.
B-E Averages of the frequency (B), peak amplitude (C), duration (D), and area (E) of hypoglossal bursts during control and immediately before, during, and $10 \mathrm{~min}$ after glybenclamide (glyb.) application. ${ }^{*} \mathrm{p}<0.05,{ }^{* *} \mathrm{p}<0.01,{ }^{* * *} \mathrm{p}<0.001$ compared with control. slices that retained respiratory rhythm, and evoked several spike-like hypoglossal bursts in one slice from a silent background. In most (seventeen of twenty-one) slices, $10 \mu \mathrm{M}$ glybenclamide failed either to cause any change of respiratory frequency (in fourteen slices) or to evoke hypoglossal bursts from a silent background (in three slices). However, at a concentration of $100 \mu \mathrm{M}$, glybenclamide completely and repeatedly reversed the changes in the frequency, the peak amplitude, the duration, and the area induced by exposure of $5 \mu \mathrm{g} / \mathrm{ml} \mathrm{LPS}$, in all the six slices tested. A sample experiment is shown in figure $4 \mathrm{~A}$, and summary data are illustrated in figure $4 \mathrm{~B}-\mathrm{E}$.

\section{L-NAME Fully Reversed the LPS-Induced Inhibition}

of Respiratory Frequency and the Intensity of Motor

Output

In six slices, after $5 \mu \mathrm{g} / \mathrm{ml}$ LPS had been applied for over $120 \mathrm{~min}$ or the respiratory rhythm had been abolished, $20 \mu \mathrm{M}$ L-NAME was applied for $10 \mathrm{~min}$. This protocol completely and repeatedly reversed the changes in the frequency, the peak amplitude, the duration, and the area induced by LPS, in all the six slices tested. A sample experiment is shown in figure $5 \mathrm{~A}$, and summary data are illustrated in figure $5 \mathrm{~B}-\mathrm{E}$.

In four of these six slices, respiratory rhythm had disappeared before application of $20 \mu \mathrm{M}$ L-NAME. For statistic comparison, the frequency value before L-NAME application was set as zero, and the values of peak ampli- tude, duration and area were averaged from the last five hypoglossal bursts after LPS application. In all these four slices, respiratory activity disappeared again after washout of L-NAME. As reference, the frequency value after washout of L-NAME was also set as zero, and the values of peak amplitude, duration and area were averaged from the last five hypoglossal bursts after L-NAME application.

\section{Discussion}

There are two major findings in the present study. First, LPS caused dose- and time-related responses of central respiratory activity. At a concentration of $0.5 \mu \mathrm{g} / \mathrm{ml}$, LPS mainly caused inhibitory responses in both the frequency and the output intensity. At a concentration of $5 \mu \mathrm{g} / \mathrm{ml}$, LPS caused an early increase of the frequency and delayed decreases in both the frequency and the output intensity. Second, L-NAME, an inhibitor of NOS, and glybenclamide, a selective inhibitor of $\mathrm{K}_{\mathrm{ATP}}$, both completely reversed the inhibitory respiratory responses to LPS application, in both the frequency and the output intensity.

To our knowledge, this is the first study that investigated the effects of direct LPS challenge on the activity of isolated respiratory centers. The results suggest that the LPS-induced responses of central respiratory activity, at least the inhibitory ones, involves overproduction of $\mathrm{NO}$ and excessive opening of $K_{\text {ATP. }}$. 


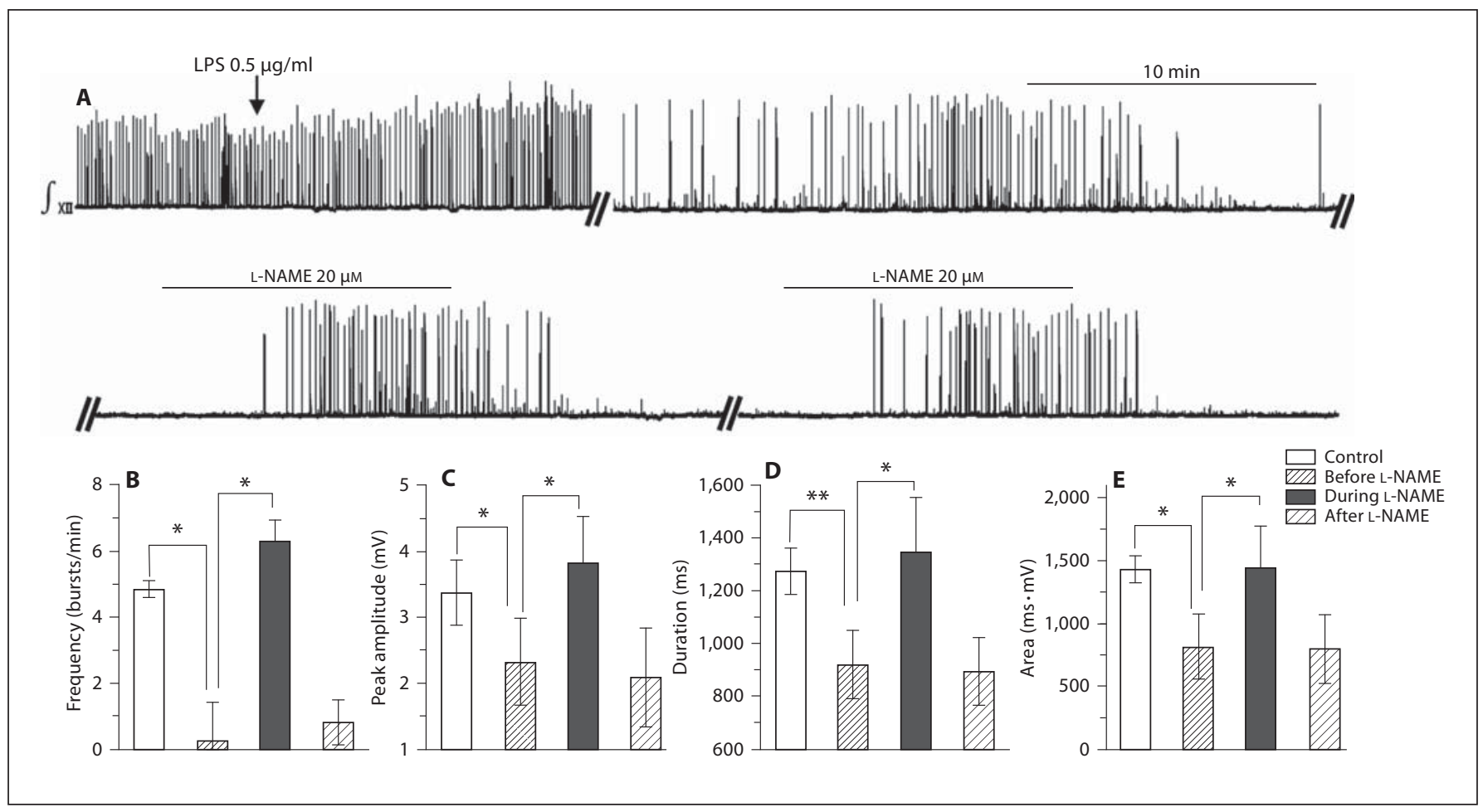

Fig. 5. L-NAME repeatedly reversed the LPS-induced inhibition of central respiratory activity. A Recording of a sample experiment, which shows that L-NAME $(20 \mu \mathrm{M})$ reversibly and repeatedly restored rhythmic hypoglossal bursts from LPS-induced re- spiratory silence. B-E Averages of the frequency (B), peak amplitude (C), duration (D), and area (E) of hypoglossal bursts during control and immediately before, during, and $10 \mathrm{~min}$ after LNAME application. ${ }^{*} \mathrm{p}<0.05,{ }^{* *} \mathrm{p}<0.01$ compared with control.
The NO/cGMP/K $\mathrm{K}_{\mathrm{ATP}}$ signaling pathway has been well documented as a preconditioning protective mechanism of the brain and many peripheral tissues in response to ischemic attack [25-27]. However, in sepsis, overproduction of $\mathrm{NO}$, and as a result the excessive opening of $\mathrm{K}_{\mathrm{ATP}}$ in vascular smooth muscles and diaphragm, has been well known to be related to the genesis of hypotension [28-31] and diaphragmatic dysfunction [32-34]; and inhibition of NO production and/or blockade of $\mathrm{K}_{\mathrm{ATP}}$ opening have been suggested as prospective procedures for sepsis treatment. Neuronal NOS (nNOS) expression in local neurons or neuronal terminals has been identified in almost all respiratory-related medullary/spinal nuclei such as the rhythmogenesis center pre-Bötzinger complex [5], respiratory motoneurons $[5,8]$, and the sensory relay nuclei of the nucleus of solitary tract (NTS) [5-8]. In sepsis, $\mathrm{NO}$ in the brain can also originate both peripherally from immune cells and centrally from CNS-resident proinflammatory cells such as microglia [35]. Since it has been clearly proven that application of $\mathrm{NO}$ donors to brainstem slices caused inhibition of respiratory rhythm and output intensity, and caused opening of single $\mathrm{K}_{\mathrm{ATP}}$ channels in respiratory-related neurons in preBötzinger complex [15], it is easy to understand that in sepsis, overproduction of $\mathrm{NO}$ and excessive opening of $\mathrm{K}_{\text {АTP }}$ in respiratory centers would cause inhibition of respiratory rhythm and output intensity; and inhibition of NOS and blockade of $\mathrm{K}_{\mathrm{ATP}}$ would reverse the LPS-induced inhibitory respiratory responses. Thus the results from the present study have added new evidence for the beneficial effects of NOS inhibition and blockade of $\mathrm{K}_{\text {ATP }}$ opening in sepsis.

NO affects not only respiratory rhythmogenesis neurons and motoneurons, but also neurons or nuclei that regulate rhythmogenesis neurons and motoneurons. Under physiological conditions, the effects of increased NO production in the brain on central respiratory activity should be the consequence of the overall effects of $\mathrm{NO}$ on both rhythmogenesis neurons/motoneurons and on their regulatory neurons or nuclei, and might be variable depending on the extent of NO increase. This possibility might be able to explain the fact that in many previous studies, NO 
mainly showed excitatory, but not inhibitory, respiratory responses. NO in the NTS has been well known to mediate the early excitatory respiratory responses to hypoxia in vivo, in both respiratory frequency and respiratory amplitude, suggesting that chemoreflex-related NTS neurons normally exert inhibitory action on central respiratory activity, and hyperpolarization of these NTS neurons by local NO production would result in disinhibition of rhythmogenesis neurons and/or respiratory motoneurons. Increasing NO supply by giving exogenous NO donors or endogenous NO biosynthesis substrate, L-arginine, increased the intensity and mostly increased the frequency of central respiratory activity; and reducing NO supply by inhibition of NOS or by scavenging of NO mainly resulted in inhibitory respiratory responses [8-14]. In one study, NO initially caused inhibitory respiratory responses in an in vitro preparation, but after mechanical isolation of a group of chemosensitive neurons in the ventrolateral medulla, the frequency response to NO was changed from inhibitory to excitatory [17], suggesting that these chemosensitive neurons normally exert excitatory action on rhythmogenesis neurons, and hyperpolarization of these chemosensitive neurons by local NO would result in inhibition of rhythmogenesis neurons. However, under severe pathological conditions, overproduction of $\mathrm{NO}$ in the brain might reach an extent that most or all respiratoryrelated neurons are silent or irresponsive, and regulatory inputs to rhythmogenesis neurons and motoneurons are nulled. This possibility might be able to explain the profound LPS inhibition of central respiratory activity in the present study, especially in the late period. Regarding the early excitatory respiratory responses of some slices to LPS, it is possible that during the initial period of LPS application, NO had not reached a very high concentration and it mainly had caused disinhibition of rhythmogenesis neurons and motoneurons by acting on regulatory neurons/ nuclei that normally exert inhibitory effect on rhythmogenesis neurons and motoneurons.

In encephalopathy or LPS-challenged brain, a variety of neuroinflammatory factors such as NO, prostaglandins, interleukin-1 $\beta$, TNF- $\alpha$, etc., have increased release and have been suggested to be involved in the genesis of encephalopathy. These neuroinflammatory factors can be produced either from peripheral immune cells, or from CNS-resident proinflammatory cells such as microglia [35]. In experimental endotoxemia of mice and rats, prostaglandins, especially prostaglandin $\mathrm{E}_{2}$ and its EP3 type of receptors in brainstem ventral respiratory group, have been proven to account almost exclusively for causing the decrease of respiratory rate in vivo $[20,21]$.
However, in the present study, both inhibition of $\mathrm{K}_{\mathrm{ATP}}$ and inhibition of NOS fully restored respiratory frequency and output intensity from LPS-induced depression, suggesting that direct LPS challenge of respiratory centers in vitro causes respiratory inhibition via different mechanisms from that of endotoxemia in vivo, and $\mathrm{NO}$ may be the common product of all the possible neuroinflammatory factors affecting respiratory centers in vitro, and $\mathrm{K}_{\text {ATP }}$ may be the final common effector.

The medullary respiratory centers include the basic rhythmogenesis center in the pre-Bötzinger complex and a variety of regulatory nuclei located from the rostral end to the caudal end. In the present study, the regulatory nuclei retained in the medullary slices might have subtle differences in the number and/or the integrity. These subtle structural differences might account for the differences in the responses to LPS. It is still under controversy whether the rhythmic activity recorded from perfused in vitro thick medulla slices or medulla-spinal preparations can represent the activity of respiratory centers in intact animals, especially because elevated potassium concentration is needed for steady recording of respiration in vitro. Even so, in vitro preparations are still widely used in studying the rhythmogenesis and regulation of respiratory centers. The main advantage is that the impact of peripheral chemo- and mechanical reflexes on respiratory centers can easily be excluded. Therefore, the present study revealed that $\mathrm{NO}$ and $\mathrm{K}_{\mathrm{ATP}}$ may be involved in the pathogenesis of abnormalities of respiratory movement induced by LPS challenge.

In conclusion, direct LPS challenge of brainstem slices altered central respiratory activity in dose- and time-related manners, in both the frequency and the output intensity; and at least the inhibitory responses involved overproduction of $\mathrm{NO}$ and excessive opening of $\mathrm{K}_{\mathrm{ATP}}$. These results suggest that the neuroinflammatory changes in respiratory centers contribute to the alterations in respiratory movement in sepsis, and both NOS and $\mathrm{K}_{\mathrm{ATP}}$ are prospective targets for treatment of respiratory dysfunctions in sepsis.

\section{Acknowledgements}

This study was supported by the Shanghai Natural Science Foundation grant 10ZR1402400, the open grant from Fudan University Institute of Brain Sciences, and the 'cross-study' grant from Fudan University Shanghai Medical College to J. Wang; and by the Sepsis Research Foundation grant 06F22DSH00403 and the Natural Science Foundation of China grant 30872459 to K. Zhu. 


\section{References}

-1 Hilaire G, Bou C, Monteau R: Rostralventrolateral medulla and respiratory rhythmogenesis in mice. Neurosci Lett 1997;224:1316.

2 Levy MM, Fink MP, Marshall JC, Abraham E, Angus D, Cook D, Cohen J, Opal SM, Vincent JL, Ramsay G; SCCM/ESICM/ACCP/ ATS/SIS: 2001 SCCM/ESICM/ACCP/ATS/ SIS International Sepsis Definitions Conference. Crit Care Med 2003;31:1250-1256.

$\checkmark 3$ Bhatia M, Moochhala S: Role of inflammatory mediators in the pathophysiology of acute respiratory distress syndrome. J Pathol 2004;202:145-156.

-4 Hameed R, Riordan FA: Meningococcal disease presenting as bronchiolitis. J Infect 2002;44:94-95.

5 Marsala J, Lukácová N, Cizková D, Kafka J, Katsube N, Kuchárová K, Marsala M: The case for the bulbospinal respiratory nitric oxide synthase-immunoreactive pathway in the dog. Exp Neurol 2002;177:115-132.

$\checkmark 6$ Haxhiu MA, Chang CH, Dreshaj IA, Erokwu B, Prabhakar NR, Cherniack NS: Nitric oxide and ventilatory response to hypoxia. Respir Physiol 1995;101:257-266.

$\checkmark 7$ Gozal D, Gozal E, Torres JE, Gozal YM, Nuckton TJ, Hornby PJ: Nitric oxide modulates ventilatory responses to hypoxia in the developing rat. Am J Respir Crit Care Med 1997; 155:1755-1762.

$>8$ Pierrefiche O, Maniak F, Larnicol N: Rhythmic activity from transverse brainstem slice of neonatal rat is modulated by nitric oxide. Neuropharmacology 2002;43:85-94.

-9 Pyatin VF, Miroshnichenko IV: Effects of nitric oxide on respiratory activity in bulbospinal preparation from rat fetus. Bull Exp Biol Med 2001;132:723-726.

-10 Pyatin VF, Miroshnichenko IV, Kul'chitskii: Role of NO-ergic mechanism in regulation of rhythmogenesis in respiratory center in bulbospinal preparation from newborn rat. Bull Exp Biol Med 2001;132:719-722.

-11 Hedrick MS, Morales RD: Nitric oxide as a modulator of central respiratory rhythm in the isolated brainstem of the bullfrog (Rana catesbeiana). Comp Biochem Physiol A Mol Integr Physiol 1999;124:243-251.

- 12 Li ZQ, Wu ZH, Shi Y, Wang NQ: Nitric oxide is involved in the modulation of central respiratory rhythm. Sheng Li Xue Bao 2003;55: 560-564.

-13 Harris MB, Wilson RJ, Vasilakos K, Taylor $\mathrm{BE}$, Remmers JE: Central respiratory activity of the tadpole in vitro brain stem is modulated diversely by nitric oxide. Am J Physiol Regul Integr Comp Physiol 2002;283:R417R428.
14 Volgin D, Volgina A, Seredenko M: Involvement of nitric oxide in regulation of the medullary respiratory rhythm in neonatal rats. Acta Neurobiol Exp (Wars) 2000;60:175186.

15 Mironov SL, Langohr K: Modulation of synaptic and channel activities in the respiratory network of the mice by NO/cGMP signalling pathways. Brain Res 2007;1130:73-82.

16 Granjeiro EM, Machado BH: NO in the caudal NTS modulates the increase in respiratory frequency in response to chemoreflex activation in awake rats. Respir Physiol Neurobiol 2009;166:32-40.

17 Volhin DV, Volhina AV, Seredenko MM: The effect of nitric oxide donors on the respiratory rhythm of an artificially superfused preparation of the brain of newborn rats Fiziol Zh 1999;45:105-110. Ukrainian.

18 Montero F, Portillo F, González-Forero D, Moreno-López B: The nitric oxide/cyclic guanosine monophosphate pathway modulates the inspiratory-related activity of hypoglossal motoneurons in the adult rat. Eur J Neurosci 2008;28:107-116.

19 Koos BJ: Central stimulation of breathing movements in fetal lambs by prostaglandin synthetase inhibitors. J Physiol 1985;362: 455-466.

-20 Olsson A, Kayhan G, Lagercrantz H, Herlenius E: IL-1 beta depresses respiration and anoxic survival via a prostaglandin-dependent pathway in neonatal rats. Pediatr Res 2003;54:326-331.

21 Hofstetter AO, Saha S, Siljehav V, Jakobsson PJ, Herlenius E: The induced prostaglandin E2 pathway is a key regulator of the respiratory response to infection and hypoxia in neonates. Proc Natl Acad Sci USA 2007;104: 9894-9899.

22 Ichikawa H, Itoh K: Blood-arachnoid barrier disruption in experimental rat meningitis detected using gadolinium-enhancement ratio imaging. Brain Res 2011;1390:142-149.

23 Banks WA, Robinson SM: Minimal penetration of lipopolysaccharide across the murine blood-brain barrier. Brain Behav Immun 2010;24:102-109.

-24 Smith JC, Ellenberger HH, Ballanyi K, Richter DW, Feldman JL: Pre-Bötzinger complex: a brainstem region that may generate respiratory rhythm in mammals. Science 1991; 254:726-729.
25 Wang L, Traystman RJ, Murphy SJ: Inhalational anesthetics as preconditioning agents in ischemic brain. Curr Opin Pharmacol 2008;8:104-110. Review.

26 Fischmeister R, Castro L, Abi-Gerges A, Rochais F, Vandecasteele G: Species- and tissue-dependent effects of NO and cyclic GMP on cardiac ion channels. Comp Biochem Physiol A Mol Integr Physiol 2005;142:136143.

27 Liu Y, Gutterman DD: The coronary circulation in diabetes: influence of reactive oxygen species on $\mathrm{K}+$ channel-mediated vasodilation. Vascul Pharmacol 2002;38:43-49.

28 O'Brien A, Stidwill RP, Clapp LH, Singer M: Variable effects of inhibiting iNOS and closing the vascular ATP-sensitive potassium channel (via its pore-forming and sulfonylurea receptor subunits) in endotoxic shock. Shock 2009;31:535-541.

29 O'Brien AJ, Thakur G, Buckley JF, Singer M, Clapp LH: The pore-forming subunit of the $\mathrm{K}(\mathrm{ATP})$ channel is an important molecular target for LPS-induced vascular hyporeactivity in vitro. Br J Pharmacol 2005; 144:367375.

30 Wilson AJ, Clapp LH: The molecular site of action of K(ATP) channel inhibitors determines their ability to inhibit iNOS-mediated relaxation in rat aorta. Cardiovasc Res 2002; 56:154-163.

-31 da Silva-Santos JE, Terluk MR, Assreuy J: Differential involvement of guanylate cyclase and potassium channels in nitric oxideinduced hyporesponsiveness to phenylephrine in endotoxemic rats. Shock 2002;17:7076.

32 Samb A, Boczkowski J, Danialou G, Lanone $\mathrm{S}$, Cisse F, Aubier M: Role of nitric oxide in diaphragmatic dysfunction genesis during sepsis in rats. Dakar Med 2000;45:126-130.

33 Comtois AS, El-Dwairi Q, Laubach VE, Hussain SN: Lipopolysaccharide-induced diaphragmatic contractile dysfunction in mice lacking the inducible nitric oxide synthase. Am J Respir Crit Care Med 1999;159:19751980

>34 Krause KM, Moody MR, Andrade FH, Taylor AA, Miller CC 3rd, Kobzik L, Reid MB: Peritonitis causes diaphragm weakness in rats. Am J Respir Crit Care Med 1998;157: 1277-1282.

35 Chakravarty S, Herkenham M: Toll-like receptor 4 on nonhematopoietic cells sustains CNS inflammation during endotoxemia, independent of systemic cytokines. J Neurosci 2005;25:1788-1796. 